\title{
How Dry is the Tropical Free Troposphere? Implications for Global Warming Theory
}

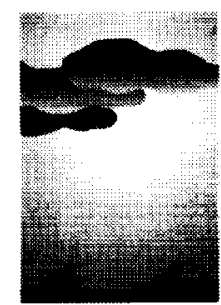

\author{
Roy W. Spencer* and William D. Braswell ${ }^{+}$
}

\begin{abstract}

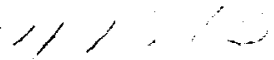

The humidity of the free troposphere is being increasingly scrutinized in climate research due to its central role in global warming theory through positive water vapor feedback. This feedback is the primary source of global warming in general circulation models (GCMs). Because the loss of infrared energy to space increases nonlinearly with decreases in relative humidity, the vast dry zones in the Tropics are of particular interest. These dry zones are nearly devoid of radiosonde stations, and most of those stations have, until recently, ignored the low humidity information from the sondes. This results in substantial uncertainty in GCM tuning and validation based on sonde data. While satellite infrared radiometers are now beginning to reveal some information about the aridity of the tropical free troposphere, the authors show that the latest microwave humidity sounder data suggests even drier conditions than have been previously reported. This underscores the importance of understanding how these low humidity levels are controlled in order to tune and validate GCMs, and to predict the magnitude of water vapor feedback and thus the magnitude of global warming.
\end{abstract}

Feedback from the redistribution of water vapour remains a substantial uncertainty in climate models. . . . Much of the current debate has been addressing feedback from the tropical upper troposphere, where the feedback appears likely to be positive. However, this is not yet convincingly established; much further evaluation of climate models with regard to observed processes is needed.

Climate Change 1995, IPCC Second Assessment

\section{Introduction}

Most global warming predicted by general circulation models (GCMs) is due to positive water vapor feedback between water vapor and surface temperature

\footnotetext{
*NASA/Marshall Space Flight Center, Global Hydrology and Climate Center, Huntsville, Alabama.

+Nichols Research Corporation, Global Hydrology and Climate Center, Huntsville, Alabama.

Corresponding author address: Dr. Roy W. Spencer, Earth System Science Division, NASA/Marshall Space Flight Center, Global Hydrology and Climate Center, ES41, Huntsville, AL 35806. In final form 23 December 1996.
}

variations (Cess et al. 1990; Zhang et al. 1994). Here we define positive water vapor feedback as a decrease in the area-averaged clear-sky outgoing longwave radiation $\left(\mathrm{OLR}_{\mathrm{ClR}}\right)$ with an areal average increase in surface temperature, due to specific humidity increases alone, where averaging occurs over entire tropospheric circulation systems.' The high level of agreement between various GCMs on the sign and magnitude of the vapor feedback has led to considerable confidence in its existence (Cess et al. 1990; Zhang et al. 1994; Intergovernmental Panel on Climate Change 1995). The turbulent boundary layer, where the air is in "direct" contact with the surface moisture source, likely contributes positively to the feedback. It is, however, less obvious how the free troposphere contributes, where detrainment of cloud condensate is the primary source of water vapor (Betts 1990; Sun and Lindzen 1993). Some research has suggested that free-tropospheric temperature and water vapor are not as closely

'Positive water vapor feedback is sometimes mistakenly inferred from differencing the OLRs and surface temperatures between the warm, moist ascending branches and the cooler, drier descending branches of tropospheric circulation systems. This will always result in a positive vapor feedback calculation, even if the true feedback, calculated over entire circulation systems, is negative. 
coupled as climate models suggest during interannual climate variations (Chou 1994; Sun and Oort 1995).

The dry subsidence zones are where much of the infrared energy that balances the solar energy being absorbed by the earth is being lost to space. (e.g., Pierrehumbert 1995). Deep convection detrains at such high altitudes in the Tropics that the relative humidities $(\mathrm{RH})$ produced in these subsidence regions have the potential of attaining the lowest values anywhere in the world. A major uncertainty is the amount of cloud condensate that detrains from the tropical precipitation systems and moistens the subsiding air through evaporation (Betts 1990; Sun and Lindzen 1993). Because this detrainment is, by definition, related to the precipitation efficiency of those systems, the handling of deep moist convection in GCMs is of obvious importance. This observation led Renno et al. (1994) to boldly conclude that, until cloud microphysical processes such as precipitation efficiency are well handled, it is premature to make climate change predictions from them.

Radiosonde information on these dry zones is scarce. A few radiosonde stations are located on the periphery of these zones (e.g., Guam and Hawaii), and even these have a history of neglecting low humidity observations ( $\mathrm{RH}<20 \%)$ and humidities at temperatures below $-40^{\circ} \mathrm{C}$. Climate sensitivity studies that depend upon tropical radiosonde data (e.g., Sinha and Allen 1994) could produce biased results if those tropical stations substantially misrepresent the true tropical tropospheric humidity distribution.

We will demonstrate that, as the tropical free troposphere becomes drier, OLR $_{\mathrm{CLR}}$ becomes more sensitive to small changes in humidity. We will show evidence from newer west Pacific radiosonde data that hints at the extreme dryness of these oceanic deserts, even though these stations are only on the periphery of a dry zone. We will then review both satellite infrared and microwave evidence for very low humidities over broad expanses of the tropical atmosphere. Finally, we will argue that a better understanding of how these low humidities are maintained is required before we can confidently predict changes in the equilibrium temperature of the earth in response to increasing greenhouse gas concentrations.

\section{OLR sensitivity to humidity}

The sensitivity of OLR $\mathrm{CLR}_{\mathrm{Co}}$ to tropical tropospheric relative humidity change is much larger at very low humidities than at very high humidities; it is also greater for changes in the free troposphere than for boundary layer humidity changes. To illustrate the latter point first, we have calculated the sensitivity of $\mathrm{OLR}_{\mathrm{CLR}}$ to additive changes of $3 \% \mathrm{RH}$ in very thin layers (Fig. 1) for the Air Force Geophysical Laboratory (AFGL) "average" tropical profiles of temperature and humidity. Also shown is the OLR sensitivity to multiplicative changes of $3 \%$ (1.03 $\times \mathrm{RH})$. This latter approach is the same taken by Shine and Sinha (1991). While they argue that sensitivity to multiplicative changes is physically meaningful, it can be misleading. Taking the extreme example of a totally dry troposphere, their method would indicate that a $3 \%$ increase in humidity would have no impact on $\operatorname{OLR}_{\mathrm{CLR}}$ (because $1.03 \times 0=0$ ). Similarly, a 3\% magnification of very small humidity values would also produce very weak impacts on OLR. As we will show, OLR $\mathrm{CLR}_{\mathrm{R}}$ is actually the most sensitive to humidity fluctuations at the lowest humidities.

We believe the most meaningful computation is the sensitivity of $O L R_{C L R}$ to small additive increments in $\mathrm{RH}$, as is shown in Fig. 1. The conclusion to be drawn from Fig. 1 is that OLR $_{C L R}$ is more sensitive to
(A)

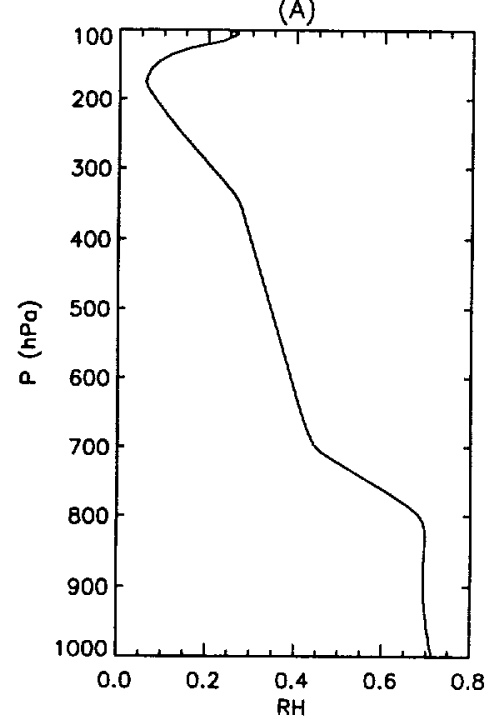

(B)

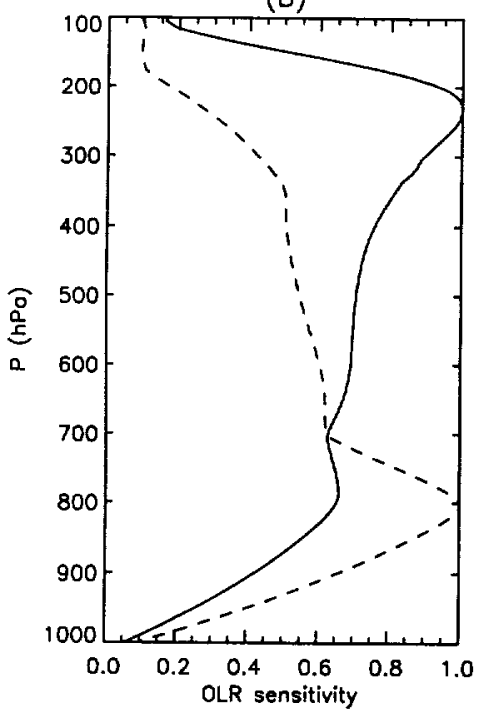

FIG. 1. For the AFGL tropical humidity profile in (a), the sensitivity of OLR to increases in $\mathrm{RH}$ in $10 \mathrm{hPa}$ layers (b). Results for additive changes of $3 \%$ in $\mathrm{RH}$ are solid, multiplicative changes of $3 \%$ in layer $\mathrm{RH}(1.03 \times \mathrm{RH})$ are dashed. The sensitivity curves are normalized to a peak value of 1 . 
humidity fluctuations in the free troposphere (above $700-800 \mathrm{hPa}$ ) than in the boundary layer (below 700-800 hPa).

The nonlinear sensitivity of OLR $\mathrm{CLR}_{\mathrm{C}}$ to $\mathrm{RH}$ changes is appreciated when our calculations in Fig. 1 are extended to progressively drier free-tropospheric air (Fig. 2). In addition to the AFGL tropical profile, we have adjusted that profile above $800 \mathrm{hPa}$ to four drier $\mathrm{RH}$ profiles (Fig 2a). By comparing the resulting OLR sensitivity profiles on the same scale (Fig. 2b), it is shown that the driest troposphere is the most sensitive to small fluctuations in $\mathrm{RH}$. The calculated clear sky OLR increases nonlinearly for these four humidity cases (Fig. 2c). Due to this nonlinear relationship, which has been addressed by Lindzen (1995), humidity fluctuations at $10 \% \mathrm{RH}$ have about three times as much impact on $\mathrm{OLR}_{\mathrm{CLR}}$ as do fluctuations around $90 \%$ $\mathrm{RH}$. If such low humidities cover a large fraction of the Tropics, then the mechanisms controlling the humidity levels of these dry zones is of obvious importance to understanding the radiation budget of the earth.

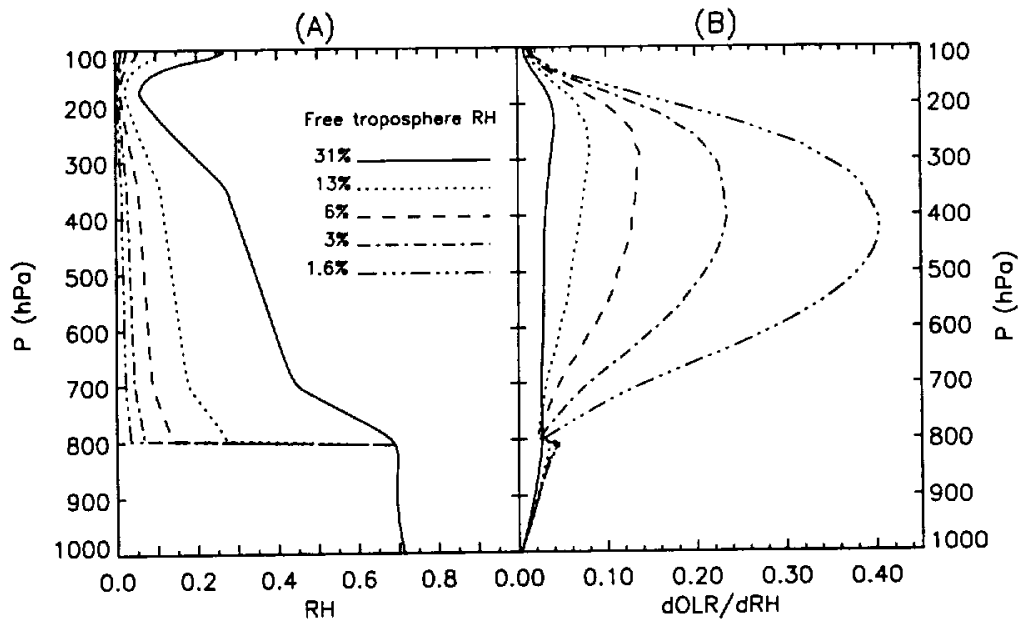

(C)

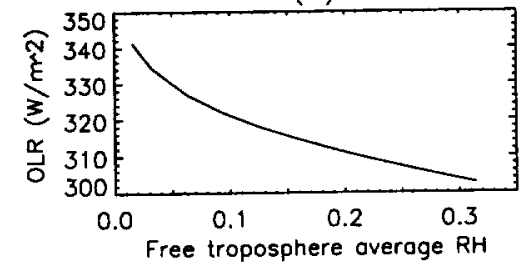

FIG. 2. (a) Progressive humidity profiles computed by reducing the freetropospheric specific humidity of the AFGL profile between 800 and $100 \mathrm{hPa}$ by multiplicative factors of $1.0,0.4,0.2,0.1$, and 0.05 . This results in height-weighted average relative humidities in the free troposphere of $31 \%, 13 \%, 6 \%, 3 \%$, and $1.6 \%$, respectively. (b) Sensitivity of OLR to additive changes of RH of $3 \%$ in 10 -hPa-thick layers as a function of the humidity profiles shown in (a). (c) The nonlinear dependence of clear-sky OLR over this range of free-tropospheric RH.

\section{Radiosonde evidence}

Despite the importance of the tropical and subtropical dry zones to the earth's radiation budget, radiosonde data have not provided much information on low humidities (Elliott and Gaffen 1991; Garand et al. 1992; Gutzler 1993). This is especially true in the subsidence regions of the Tropics where virtually no stations exist. Most of the tropical sonde data that are available are from U.S.-controlled stations utilizing the VIZ sondes. These sondes carry a carbon hygristor whose response is calibrated in terms of relative humidity through laboratory measurements. Until 1993, U.S.-controlled stations ignored humidities below $20 \%$ and temperatures below $-40^{\circ} \mathrm{C}$. As discussed by Wade (1994), this was not due to a limitation of the sonde itself but of data reduction procedures. Therefore, a combination of spatial sampling and data processing procedures have conspired to leave a gaping hole in our understanding of these oceanic deserts.
Some evidence for the existence of very low humidities in the tropical free troposphere can be gathered from individual radiosonde soundings at four west Pacific radiosonde stations that are on the periphery of one of these dry zones during Northern Hemisphere winter. Relative humidities from 1600 VIZ sonde observations from Yap, Koror, Ponape, and Truk during January-May of 1994 and 1995 were combined into a histogram at pressure levels from 1000 to $100 \mathrm{hPa}$ (Fig. 3). Most of the pressure levels above $850 \mathrm{hPa}$ exhibit frequency distributions that have an approximate log-normal shape. The levels below about $700 \mathrm{hPa}$ are seen to be quite moist, generally $70 \%-90 \%$, as would be expected for the turbulent boundary layer with the tropical ocean as a moisture source. Immediately above the boundary layer, we observe frequent instances of much drier conditions, with a peak in the frequency distribution near $15 \% \mathrm{RH}$ between 500 and $250 \mathrm{hPa}$. This separation of humidity regimes is clear evidence of the very different processes controlling boundary layer versus free-tropospheric humidity (Sun and Lindzen 1993). As one 


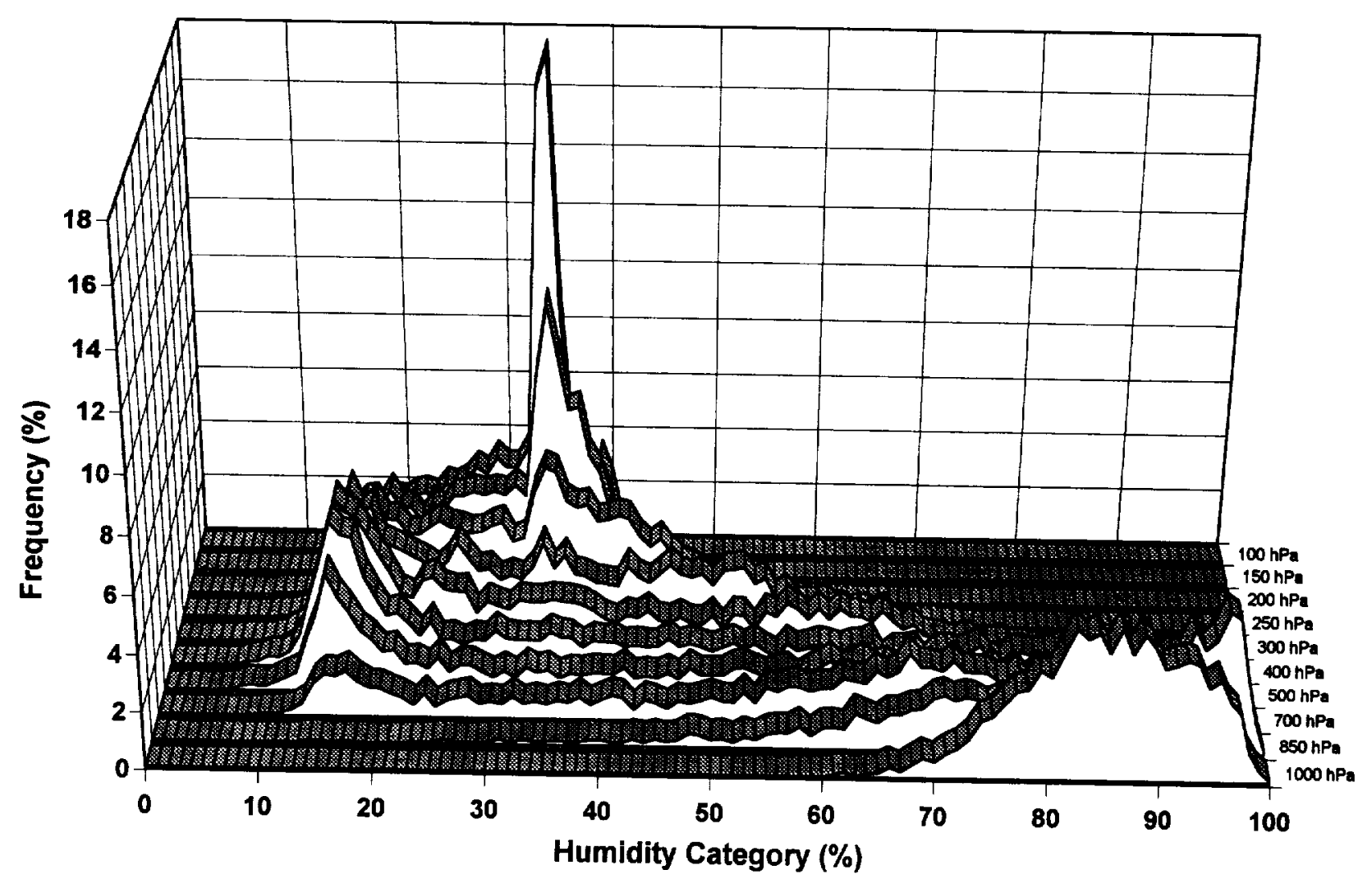

Fig. 3. Frequency histograms of VIZ sonde relative humidities at pressure levels from 1000 to $100 \mathrm{hPa}$ for a total of $1600 \mathrm{sonde}$ ascents at Yap, Koror, Ponape, and Majuro in the tropical western Pacific during January-May of 1994 and 1995.

proceeds higher, ${ }^{2}$ the average humidity moistens to form a peak near $35 \% \mathrm{RH}$ below the tropical tropopause, which is usually near $100 \mathrm{hPa}$.

In summary, these four west Pacific stations exhibit a very moist boundary layer, often overlain by very dry air in the lower free troposphere, which is in turn overlain by moister air in the upper troposphere. This is conceptually consistent with Sun and Lindzen (1993), who examined deep convection as the primary source of free-tropospheric humidity through detrainment by deep convective precipitation systems. As the condensate detrained into the upper troposphere by deep convection subsides and evaporates, it moistens the air, but the RH-drying effect of the subsidence-induced warming overwhelms the moistening. This results in a lowering of RH as air parcels move from the upper to the lower free tropo-

\footnotetext{
${ }^{2}$ All relative humidities discussed in this article are with respect to saturation over water, not ice. Thus, a $35 \%$ humidity at $150 \mathrm{hPa}$ occurs at such low temperatures that we would expect saturation to occur with respect to ice, not water. Relative humidity = $35 \%$ at $150 \mathrm{hPa}$ then becomes about $70 \%$ with respect to ice saturation at the average temperature of $-67^{\circ} \mathrm{C}$.
}

sphere. This is also consistent with data from the Stratospheric Aerosol and Gas Experiment (SAGE; McCormick et al. 1993), which produced a climatology of tropical humidities for the upper troposphere for cloud-free regions of the Tropics. It too showed the upper troposphere to be somewhat moister than the middle troposphere, with zonally averaged humidities quite low, between $10 \%$ and $20 \%$.

Is this sampling of radiosonde data from these four west Pacific stations representative of the dry zones of the Tropics? We will show satellite evidence that the driest humidities from the sondes are probably still too moist to be representative of the dry zones. There is calibration evidence from the sondes themselves that lead to the same conclusion. Wade (1994) examined in detail the history of the National Weather Service procedures for not reporting RH below $20 \%$. Despite the lifting of this moratorium in 1993, newer laboratory calibration data were not included for converting the carbon hygristor resistances to humidity at low humidities. According to Wade, this has led to an artificial lower limit on VIZ humidities of about $13 \%-14 \%$, which is consistent with the peak in the midtropospheric frequency distributions shown in 
Fig. 3. Therefore, even these new VIZ sonde low humidity reports presented in Fig. 3 have a moist bias.

\section{Satellite measurements}

Satellite infrared radiometers with water vapor sounding channels have begun to reveal the aridity of the tropical subsidence zones. In particular, the $6.7-\mu \mathrm{m}$ channels of the High Resolution Infrared Sounder (HIRS) carried by the National Oceanic and Atmospheric Administration's polar orbiters and by the Geostationary Operational Environmental Satellite (GOES) and Meteosat geostationary satellites have been most utilized for this purpose. For instance, Salathe et al. (1995) showed that, compared to HIRS 6.7- $\mu \mathrm{m}$ observations, the Goddard Laboratory for Atmospheres GCM did not dry the troposphere sufficiently in the subsidence zones when forced with SST anomalies associated with El Niño-Southern Oscillation (ENSO) events. Other model comparisons to the water vapor channel data were made for the European Centre for Medium-Range Weather Forecasts (ECMWF) and the National Center for Atmospheric Research Community Climate Model (NCAR CCM) by Soden and Bretherton (1994); by Chen et al. (1996) for the fourth-generation Hamburg climate model (ECHAM) GCM; and by Schmetz and van de Berg (1994) for ECMWF compared to the Meteosat water vapor channels. A common theme has been that the models' analyses were not dry enough in the dry zones, which was attributed by Salathe et al. to convective parameterization insufficiencies. More recent retrievals with 6.7- $\mu \mathrm{m}$ data (Stephens et al. 1996) suggest that inclusion of the water vapor continuum absorption can reduce retrieved humidities even further. We will present new passive microwave evidence that these dry zones are at least as dry as the infrared studies have suggested.

The Special Sensor Microwave humidity sounder (SSM/T-2) flying on the Defense Meteorological Satellite Program (DMSP) $F-11$ and $F-12$ satellites has three water vapor sounding channels at $183.3 \pm 1 \mathrm{GHz}$, $\pm 3 \mathrm{GHz}$, and $\pm 7 \mathrm{GHz}$. The data are calibrated in terms of brightness temperature $\left(T_{b}\right)$ through linear interpolation between a cosmic background view (assumed to be $2.7 \mathrm{~K}$ ) and a view of an onboard high emissivity calibration target whose temperature is monitored with redundant platinum resistance thermometers. This is the same calibration strategy utilized for the Microwave Sounding Unit (MSU) data used by Spencer and Christy (1992) for global tem- perature monitoring. The SSM/T-2 spatial resolution at nadir is approximately $50 \mathrm{~km}$, and 28 measurements (footprints) make up a single scan line. Aircraft underflights of this instrument have helped to validate the absolute accuracy of the $T_{b}$, which should not be worse than about $1^{\circ}-2^{\circ} \mathrm{C}$ (Falcone et al. 1992). The rms noise of individual footprint measurements is approximately $0.4^{\circ}-0.6^{\circ} \mathrm{C}$. Because we will be interpreting $T_{b}$ values very close to the temperature of the warm target, any uncertainties arising from interpolation between it and the cosmic background temperature are greatly reduced. Furthermore, because an incremental change in relative humidity causes the largest change in $T_{b}$ at the driest humidities, we have highest confidence in the lowest humidity inferences made from the system.

While a microwave measurement is much less sensitive to cirrus cloud contamination than is an infrared measurement, the microwave measurements are still degraded if thick, ice-laden clouds are present. Under these heavy cloud conditions the microwave $T_{h}$ will have a cold bias, which would be misinterpreted as excess water vapor. In our analysis, all $T_{h}$ that fall below a threshold corresponding to $100 \%$ saturation with respect to an ice-water mixture are set to that threshold value. In the context of this study, any remaining contamination will cause high humidity regions to be too humid, while dry regions should have little if any residual contamination.

The retrieval of humidity profiles from satellite sounder channels is complicated by assumptions about the vertical distribution of humidity (e.g., Braswell and Spencer 1996). Here we have chosen to use the method of Soden and Bretherton (1993), who introduced a simple interpretation of the $T_{b}$ in terms of a weighting function-weighted average relative humidity. While that method was developed for the infrared water vapor channels, we will show that it can be applied to the SSM/T-2 183.3-GHz channels as well. Of particular interest will be the finding that the microwave observations produce relative humidities considerably drier than the infrared observations in the dry zones. Possible explanations for this discrepancy in terms of maximum sensitivity of the IR measurements to cirrus hydrometeors and/or the broadness of the IR weighting functions will also be discussed.

The three SSM/T-2 channels' weighting functions are shown in Fig. 4 for two of the moisture profiles shown in Fig 2: the AFGL tropical profile and the average $\mathrm{RH}=6 \%$ profile. It can be seen that the altitude of sensitivity to humidity increases with humid- 

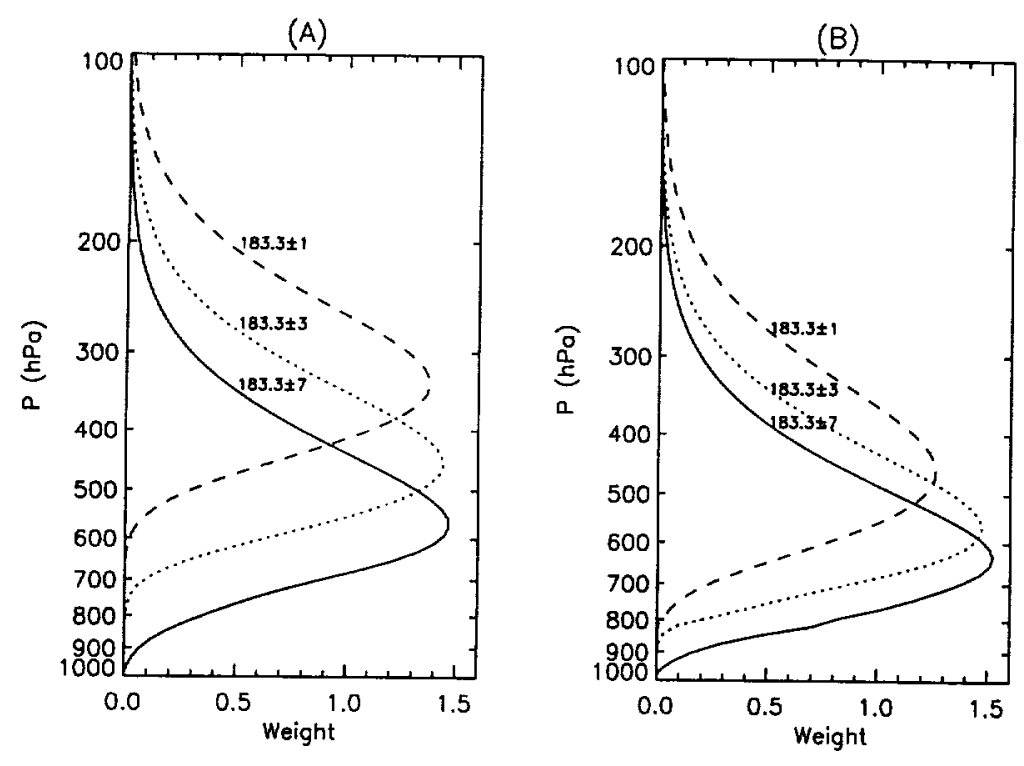

FIG. 4. (a) Weighting functions for the SSM/T-2 $183-\mathrm{GHz}$ channels for the AFGL tropical profile and (b) a humidity profile created by reducing the freetropospheric $\mathrm{RH}$ in the AFGL tropical profile by a factor of 0.2 . The heightweighted free-tropospheric RH for (a) and (b) is $31 \%$ and $6 \%$, respectively. These weighting functions represent the sensitivity of brightness temperature to additive changes of RH in thin layers of constant thickness in log pressure. The curves have been normalized to give an area of 1 when integrated over log pressure. plies to the infrared humidity sounding channels as well.

Below, we will interpret the $T_{b}$ in terms of relative humidity. But first we will compare the satellite measured $T_{b}$ to those calculated from radiosonde ascents at Guam during 1994. This is the most straightforward comparison that can be made between the satellite and radiosonde data. For Guam (Fig. 5) we find that the warmest (and thus driest) $\mathrm{T}_{\mathrm{b}}$ are about $10^{\circ} \mathrm{C}$ warmer in the satellite data than when calculated from the sonde data. This was also true for Hawaii, and Key West, Florida (not shown). This is a substantial difference and supports the reported tendency of the VIZ sondes to be too moist at low humidities, as discussed above.

We now examine the quantitative interpretation of the SSM/T-2 $\mathrm{T}_{\mathrm{b}}$ in terms of RH. Following Soden and Bretherton (1993), we find their logarithmic transform between $T_{b}$ and weighting function-weighted $\mathrm{RH}$ provides an excellent correlative relaity. In the presence of a substantial lapse rate, as is characteristic of the Tropics, this means that the more humid the atmosphere, the colder the $\mathrm{T}_{\mathrm{b}}$; the drier the air, the warmer the $T_{b}$. The same interpretation ap- tionship when applied to numerous radiosonde profiles from Guam at the SSM/T-2 channel frequencies (Fig. 6). The solid lines in Fig. 6 represent best fits of the Soden and Bretherton formula,
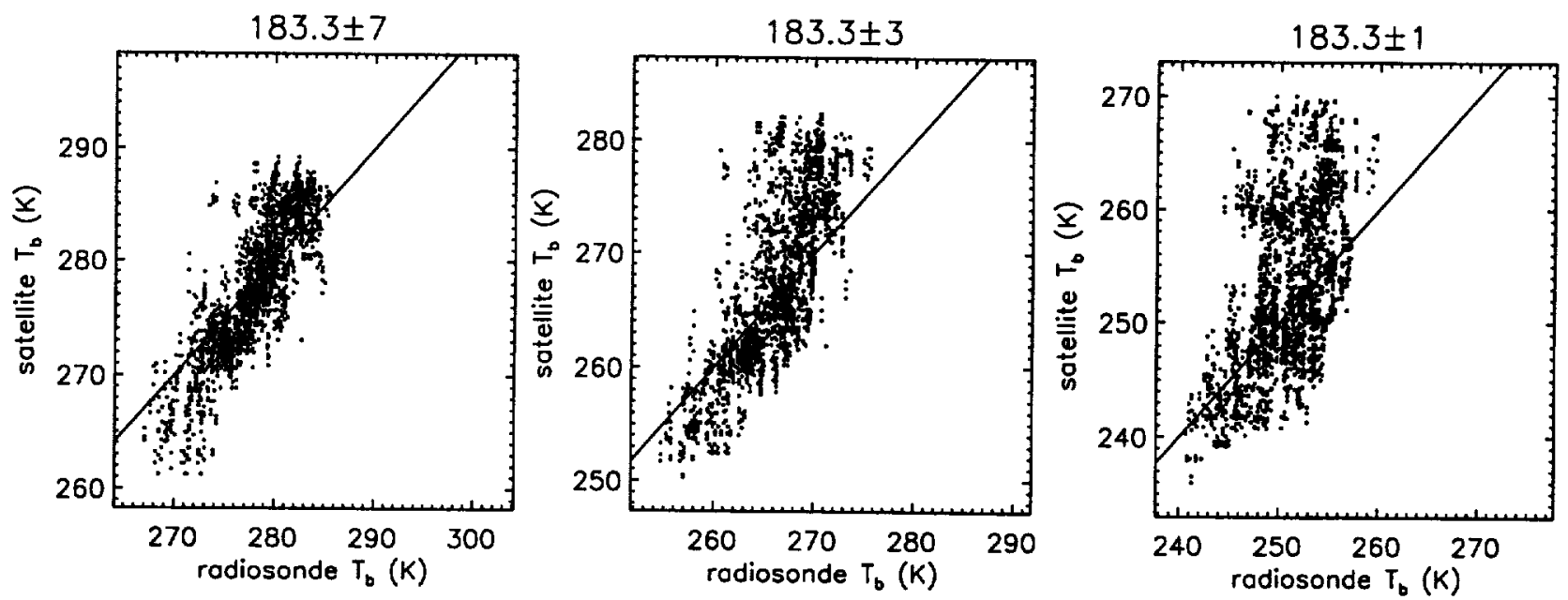

FIG. 5. Comparison of SSM/T-2 brightness temperatures measured near Guam to brightness temperatures computed from radiosonde soundings at Guam. Each point matches a single satellite brightness temperature to a brightness temperature computed from a single sonde ascent on the same day. Only satellite measurements within $100 \mathrm{~km}$ of the sonde station were used. In an attempt to remove the effects of ice scattering in deep convective regions, only satellite measurements on a given day within the $100-\mathrm{km}$ radius and with a spatial standard deviation of less than $2 \mathrm{~K}$ were included. All possible pairs of satellite measurements and sonde measurements on a given day are plotted. When computing the sonde brightness temperature, the view angle of the satellite measurement being paired with was used. 
$183.3 \pm 7$

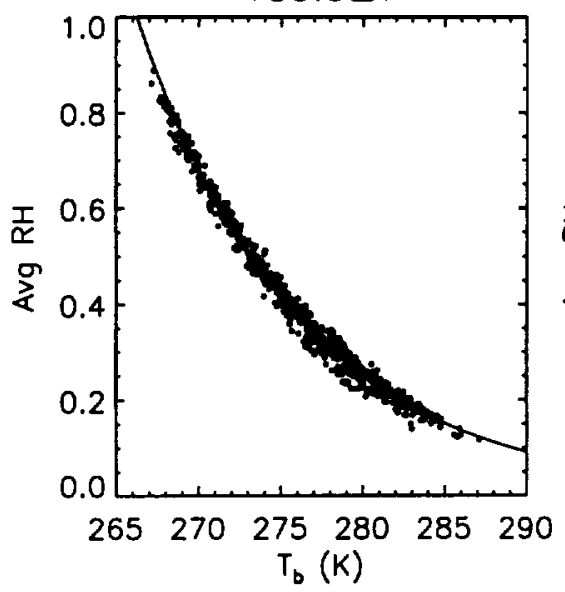

$183.3 \pm 3$

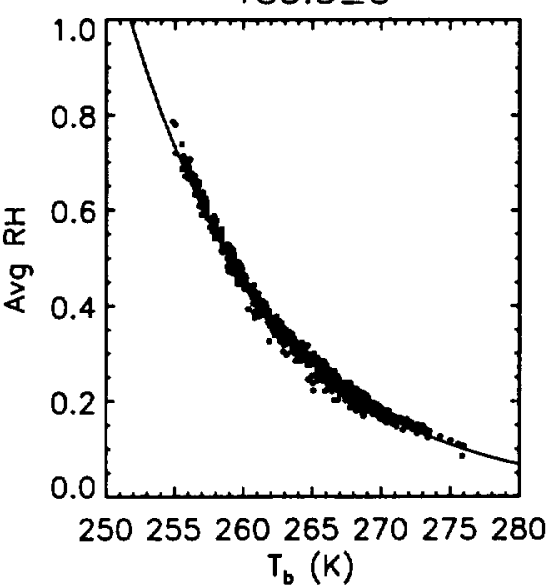

$183.3 \pm 1$

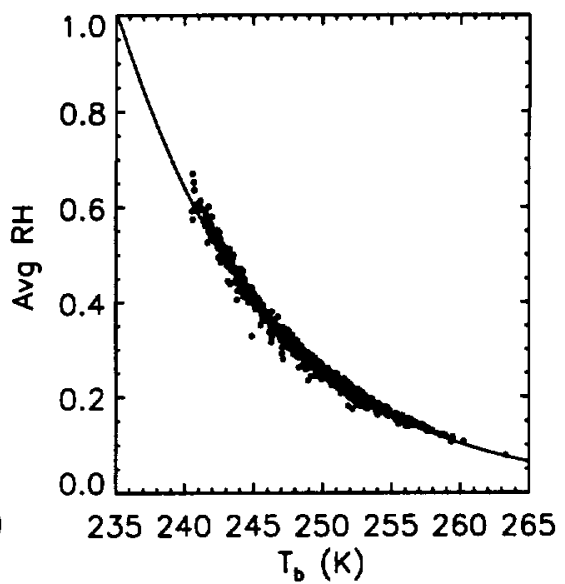

FIG. 6. Comparison of synthetic 183.3-GHz brightness temperatures to weighting function weighted RH for radiosonde soundings at Guam from 1994. The brightness temperatures were computed using a microwave radiative transfer model. The solid lines represent best-fit regression curves of the form $\ln (\mathrm{RH})=\alpha+\beta \mathrm{T}_{\mathrm{b}}$. The residual standard deviations for the fits were $1.9 \% \mathrm{RH}, 1.4 \% \mathrm{RH}$, and $1.4 \% \mathrm{RH}$ for the $183.3 \pm 7,183.3 \pm 3$, and $183.3 \pm 1-\mathrm{GHz}$ channels, respectively.

$$
\ln (\mathrm{RH})=a+b \mathrm{~T}_{\mathrm{b}}
$$

to the sonde data. Very little difference in diagnosed humidities were found when Key West data were used for training instead of Guam data. The relationship in (1) was applied to limb-corrected $T_{b}$ from the 183.3$\mathrm{GHz}$ channels of the SSM/T-2 to compute tropical relative humidity.

While it has been common for the results of the satellite infrared humidity retrievals to be presented as monthly, seasonal, or annually averaged fields, the nonlinear relationship between humidity and $\mathrm{OLR}_{\mathrm{CLR}}$ suggests that daily gridpoint humidity information is necessary to correctly infer the net time- and spaceaveraged OLR $_{C L R}$ effects from the humidity fields. First, frequency histograms of daily gridpoint $\mathrm{RH}$ from the $183.3 \pm 1-\mathrm{GHz}$ channel $\left(\mathrm{RH}_{t 1}\right.$, Fig. 7) illustrate the extreme dryness of much of the area within the Tropics $\left( \pm 30^{\circ}\right.$ latitude). A peak is seen in the frequency distribution at $9 \%$ during January 1994 and at 6\% during July 1994. Approximately one-half of the Tropics are covered by $\mathrm{RH}_{ \pm 1}<20 \%$. Individual gridpoint humidities fall as low as $2 \%$. Because near saturation of the tropical free troposphere is only found within and in the vicinity of deep convection, relatively few observations reach the saturation range of $60 \%-80 \%$ (assuming some saturation is with re- spect to ice or an ice-water mixture for the $\pm 1 \mathrm{GHz}$ channel). Humidity frequency distributions for the \pm 3 channel $\left(\mathrm{RH}_{ \pm 3}\right)$ reveal slightly moister conditions, and the \pm 7 channel $\left(\mathrm{RH}_{ \pm 7}\right)$ indicates still higher humidities. This is qualitatively consistent with Soden and Bretherton (1996), who also found average drying from the middle to the upper troposphere based on HIRS 6.7-, 7.3-, and 8.3- $\mu \mathrm{m}$ data. The higher humidities in the lowest peaking channel seem reasonable in light of its substantial contribution from the moist boundary layer. However, the upper $( \pm 1 \mathrm{GHz})$ channel being slightly drier than the middle $( \pm 3 \mathrm{GHz}$ ) channel seems peculiar in light of the radiosonde and SAGE evidence presented earlier for subsidenceinduced drying of the midtroposphere. Based upon our
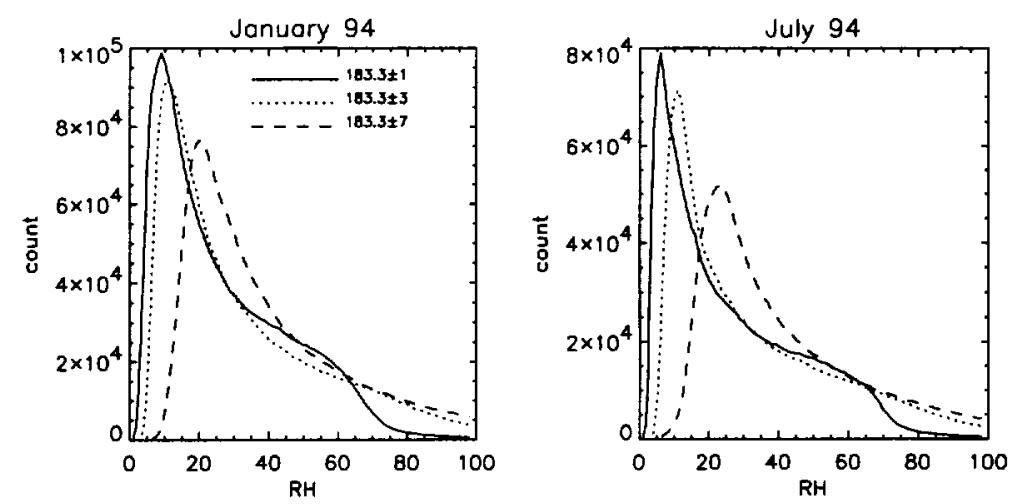

FIG. 7. Frequency distributions for daily tropical SSM/T-2 relative humidity for January and July 1994. The total number of measurements differ for the two months because of missing days in July. 

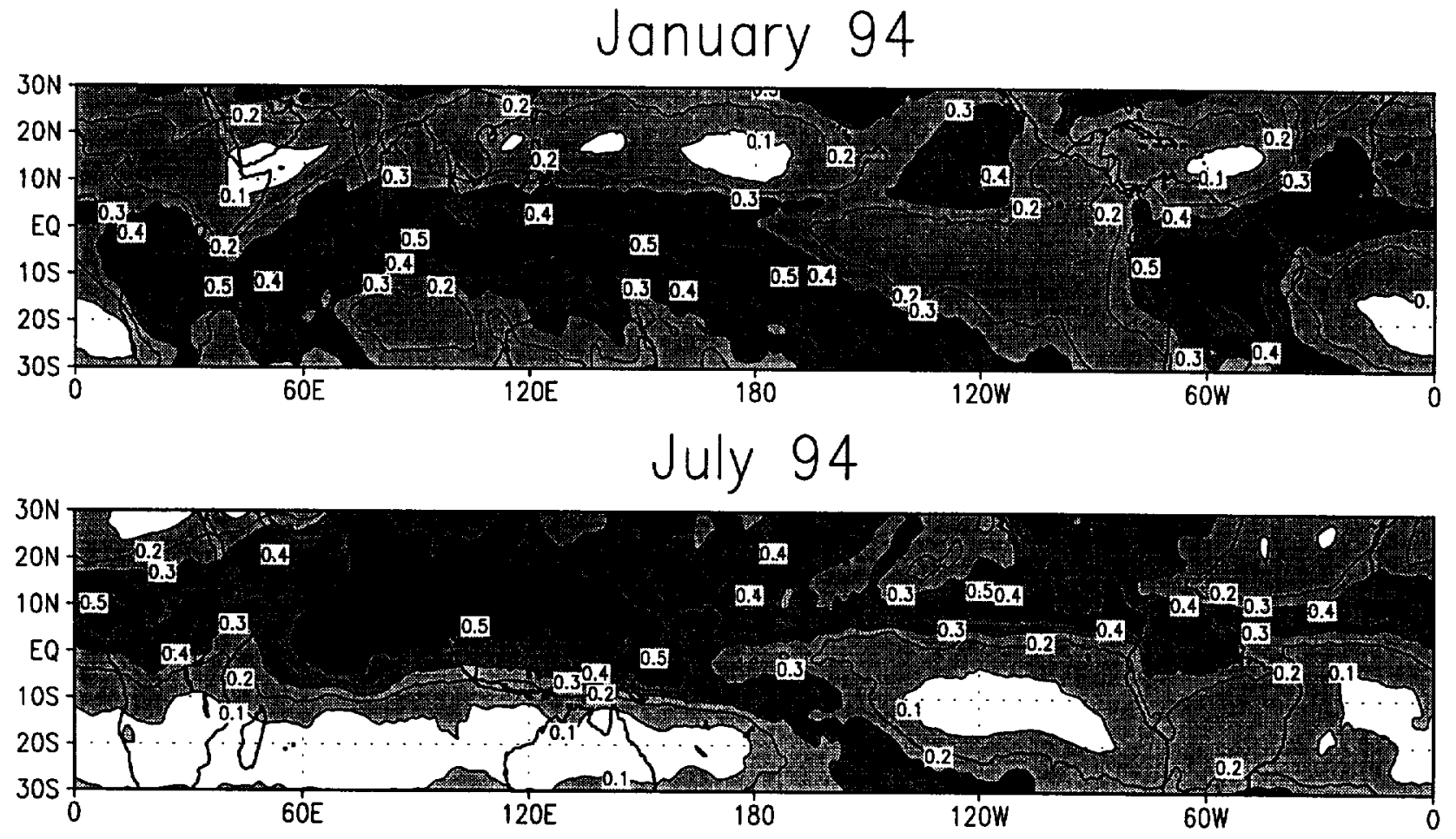

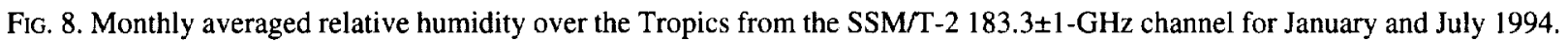
The SSM/T-2 channels provide RH weighted by the channel $T_{b}$ sensitivity weighting function, for example, those shown in Fig. 4 .

analysis of individual radiosondes at Guam during the winter dry season, we believe this is the result of the midtroposphere $\pm 3-\mathrm{GHz}$ channel weighting function picking up some signal from the very moist boundary layer, where the relative humidity averages $80 \%-$ $90 \%$.

Monthly average gridpoint $\mathrm{RH}_{ \pm 1}$ are shown in Fig. 8 for January and July 1994. Even on monthly timescales, areas are seen for which average $\mathrm{RH}_{ \pm 1}$ falls below $10 \%$. These humidities are about $5 \%-10 \%$ lower than those calculated from $6.7-\mu \mathrm{m}$ data by Chen et al. (1996). They are somewhat closer to, but still drier than, the humidities calculated by Stephens et al. (1996) from 6.7- $\mu \mathrm{m}$ data. Stephens et al. included water vapor continuum absorption in their calculations and state that uncertainties in the value of this absorption can cause $15 \%-25 \%$ uncertainty in the relative humidity estimates from the infrared data, although the uncertainty is reduced to about $5 \%$ at $\mathrm{RH}=20 \%$. Because the microwave observations are dominated by the water vapor emission line absorption at $183.3 \mathrm{GHz}$, they are not affected by this source of uncertainty. Thus, the microwave humidities might even help to determine the magnitude of the infrared continuum absorption.
Another potential source for the disagreement between the infrared and microwave humidities is weighting function shape. There is some evidence that the $6.7-\mu \mathrm{m}$ weighting function is broader than that at $183.3 \pm 1 \mathrm{GHz}$. This would cause additional moistening of the very dry midtropospheric signal through vertical averaging with higher humidities above and below the dry midtroposphere. We are working with B. Soden to understand these differences.

\section{Summary and conclusions}

We have shown that clear-sky OLR $_{\mathrm{CLR}}$ fluctuations are most sensitive to humidity fluctuations in the middle and upper tropical free troposphere and that this sensitivity is greatest at the lowest humidities. Tropical radiosondes have only hinted at the geographical extent and potential aridity of tropical freetropospheric air, due to a combination of poor spatial sampling and a continuing moist bias in the VIZ sonde-computed humidities at the dry end of the scale.

Satellite infrared humidity measurements in recent years have revealed moist biases in GCMs and numerical weather prediction models. Adding to this 
evidence, we have presented new passive microwave humidity sounder data that reveal even drier conditions than have been reported by the infrared sounders, with a peak in the tropical frequency distribution of $\mathrm{RH}_{ \pm 1}$ between $5 \%$ and $10 \%$; approximately one-half of the Tropics are covered by $\mathrm{RH}_{ \pm 1}<20 \%$. Some of the daily humidity measurements fall to about $2 \%$.

The nonlinear sensitivity of clear-sky OLR to humidity fluctuations at low humidities makes the newer satellite evidence of extreme aridity of particular importance to global warming predictions from GCMs. Because the source of most tropical free-tropospheric humidity is cloud detrained from deep convective systems, accurate GCM convective parameterizations of cloud microphysical processes, such as precipitation efficiency, are ultimately required to match the observed humidity distributions. As the climate system warms or cools, any changes in these microphysical processes must also be known in order to correctly predict the associated humidity changes and thus changes in OLR and the water vapor feedback on temperature. Thus, the evidence for widespread dry air makes accurate convective parameterizations even more critical for global warming predictions.

Acknowledgments. We thank Bert Eskridge of NCDC for provision of the radiosonde data. We also wish to thank Dick Lindzen for several stimulating discussions during the course of this research. This research was supported by NASA's Office of Mission to Planet Earth.

\section{References}

Betts, A. K., 1990: Greenhouse warming and the tropical water vapor budget. Bull. Amer. Meteor. Soc., 71, 14651467.

Braswell, W. D., and R. W. Spencer, 1996: A statistical approach for retrieval of humidity profiles from SSM/T-2: Comparison to a physical retrieval method. Preprints, Eighth Conf. Satellite Meteorology and Oceanography, Atlanta, GA, Amer. Meteor. Soc., 15-18.

Cess, R. D., and Coauthors, 1990: Intercomparison and interpretation of climate feedback processes in 19 atmospheric general circulation models. J. Geophys. Res., 95, $16601-$ 16615 .

Chen, C.-T., E. Roeckner, and B. J. Soden, 1996: A comparison of satellite observations and model simulations of columnintegrated moisture and upper tropospheric humidity. J. Climate, 9, 1561-1585.

Chou, M.-D., 1994: Coolness in the tropical Pacific during an El Niño episode. J. Climate, 7, 1684-1692.

Elliott, W. P., and D. J. Gaffen, 1991: On the utility of radiosonde humidity archives for climate studies. Bull. Amer. Meteor. Soc., 72, 1507-1520.
Falcone, V. J., and Coauthors, 1992: SSM/T-2 calibration and validation data analysis. Environmental Research Papers No. 1111,108 pp. [Available from Phillips Laboratory, Hanscom Air Force Base, MA 01731-5000.]

Garand, L., C. Grassotti, J. Halle, and G. L. Klein, 1992: On differences in radiosonde humidity reporting practices and their implications for numerical weather prediction and remote sensing. Bull. Amer. Meteor. Soc., 73, 1417-1423.

Gutzler, D. S., 1993: Uncertainties in climatological tropical humidity profiles: Some implications for estimating the greenhouse effect. J. Climate, 6, 978-982.

Intergovernmental Panel on Climate Change, 1995: Climate Change 1995: The Second IPCC Assessment. University Press, 572 pp.

Lindzen, R. S., 1990: Some coolness concerning global warming. Bull. Amer. Meteor. Soc., 71, 288-299.

- 1995 : The importance and nature of the water vapor budget in nature and models. Climate Sensitivity to Radiative Perturbations: Physical Mechanisms and their Validation, H. Le Trevt, Ed., NATO ASI Series 1: Global Environmental Change, Vol. 34, Springer-Verlag. 51-66.

McCormick, M. P., E. W. Chiou, L. R. McMaster, W. P. Chu, J. C. Larsen, D. Rind, and S. Oltmans, 1993: Annual variations of water vapor in the stratosphere and upper troposphere observed by the Stratospheric Aerosol and Gas Experiment II. J. Geophys. Res., 98, 4867-4874.

Pierrehumbert, R. T., 1995: Thermostats, radiator fins, and the local runaway greenhouse. J. Atmos. Sci., 52, 1784-1806.

Renno, N. O., K. A. Emanuel, and P. H. Stone, 1994: Radiativeconvective model with an explicit hydrologic cycle 1. Formulation and sensitivity to model parameters. J. Geophys. Res., 99, $14429-14441$.

Salathe, E. P., D. Chesters, and Y. C. Sud, 1995: Evaluation of the upper-tropospheric moisture climatology in a general circulation model using TOVS radiance observations. J. Climate, 8, 2404-2414.

Schmetz, J., and L. van de Berg, 1994: Upper-tropospheric humidity observations from METEOSAT compared with short term forecast fields. Geophys. Res. Left., 21, 573-576.

Shine, K. P., and A. Sinha, 1991: Sensitivity of the earth's climate to height dependent changes in the water vapor mixing ratio. Nature, 354, 382-384.

Sinha, A., and M. R. Allen, 1994: Climate sensitivity and tropical moisture distribution. J. Geophys. Res., 99, 3707-3716.

Soden, B. J., and F. P. Bretherton, 1993: Upper tropospheric relative humidity from the GOES $6.7 \mu \mathrm{m}$ channel: Method and climatology for July 1987. J. Geophys. Res., 98, $16669-$ 16688 .

- , and - 1994: Evaluation of water vapor distribution in general circulation models using satellite observations. J. Geophys. Res., 99, 1187-1210.

$\longrightarrow$, and - 1996: Interpretation of TOVS water vapor radiances in terms of layer-average relative humidities: Method and climatology for the upper, middle, and lower troposphere. J. Geophys. Res., 101, 9333-9343.

Spencer, R. W., and J. R. Christy, 1992: Precision and radiosonde validation of satellite gridpoint temperature anomalies. Part I: MSU channel 2. J. Climate, 5, 847-857.

Stephens, G. L., D. L. Jackson, and I. Wittmeyer, 1996: Global observations of upper-tropospheric water vapor derived from TOVS radiance data. J. Climate, 9, 305-326. 
Sun, D.-Z. and R. S. Lindzen, 1993: Distribution of tropical tropospheric water vapor. J. Atmos. Sci., 50, 1643-1660.

_-., and A. H. Oort, 1995: Humidity-temperature relationships in the tropical troposphere. J. Climate, 8, 1974 1987.
Wade, C. G., 1994: An evaluation of problems affecting the measurement of low relative humidity on the United States radiosonde. J. Atmos. Oceanic Technol., 11, 687-700.

Zhang, M. H., J. J. Hack, J. T. Kiehl, and R. D. Cess, 1994: Diagnostic study of climate feedback processes in atmospheric general circulation models. J. Geophys. Res., 99, 5525-5537.

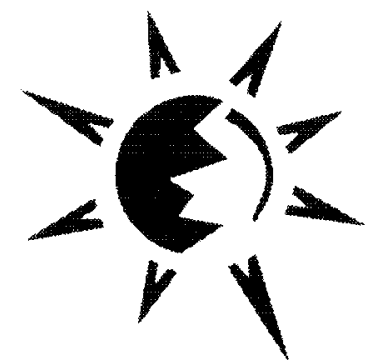

